\title{
Synthesis, Characterization and Thermal Properties of phenol- formaldehyde polymer based nickel nanoparticles
}

\author{
Giriraj Tailor $^{1 *}$, Jyoti Chaudhary ${ }^{2}$, Saurabh Singh $^{3}$, Deepshikha Verma ${ }^{4}$ \\ ${ }^{1}$ Department of Polymer Science, M.L.S University, Udaipur, Rajasthan, India, 313001 \\ ${ }^{2}$ Department of Chemistry, M.L.S University, Udaipur, Rajasthan, India, 313001 \\ ${ }^{3}$ Department of Chemistry M.L.V. Govt. College, Bhilwara, Rajasthan, India, 311001 \\ ${ }^{4}$ Department of Chemistry, Mewar University, Chittorgarh, Rajasthan, India, 312901 \\ Email-giriraj.tailor66@gmail.com
}

\begin{abstract}
In this scientific research, thermally stable nickel nanoparticles were synthesized and characterized. Nickel nanoparticles were synthesized using phenol -formaldehyde by chemical method followed by calcination. The polymer metal complex was confirmed by FTIR and NMR. The spherical morphology of nickel nanoparticles confirmed by SEM. The crystallographic structure is confirmed by XRD and size of cobalt nanoparticles is $24.0 \mathrm{~nm}$. The TGA analysis was performed over a range of $29-600^{\circ} \mathrm{C}$. The TGA thermograph predicts mass decomposition of $11 \%$, for nickel phenol-formaldehyde nanocomposite. The decomposition rate of composites is very low $2 \%$ weight loss per $100^{\circ} \mathrm{C}$ increment in temperature.
\end{abstract}

Keywords- Nickel, nanoparticles, Thermal, FTIR, SEM.

\section{Introduction-}

The transition metal nickel shows distinct magnetic, thermal and catalytic properties [1-2]. In the form of Nano size -nickel has versatile application in the field of biomolecular separation [3] pharmaceutical synthesis [4] magnetic biocatalysis [5] biosensor [6] In the literature, there are reports on the preparation and properties of novel nickel nanomaterials such as sea-urchin like nickel nanoparticles [7] tetragonal nickel nanoparticles [8] conical nickel nanorods [9], triangular and hexagonal nickel nanosheet [10] and nickel nanochain [11-12].

The unusual properties and prospective application of metal nanoparticles in optical, catalytic, thermal, magnetic material with corresponding bulk metal [13]. A various method has been developed for the preparation of metal nanoparticles such as solvent extraction reduction, micro emulsion techniques, photocatalytic reduction, polyol process and alcohol reduction [14]. Numerous chemical and physical methods have been used to produce metal nanoparticles, such 
as metal evaporation [15] metal salt reduction [16] laser ablation techniques [17] electrochemical method [18] sonochemical synthesis [19] neutral organometallic precursor decomposition [20] Generally, chemical synthesis method over advantage of low cost and simplicity with physical approaches. One of the great significance to prepare high-quality $\mathrm{Ni}$ nanomaterials of specificity using convenient and low-cost methods. Similar findings have been reported for nickel nanoparticles [21]. Many studies have shown that the nickel, cobalt and iron nanoparticles have thermal properties [22 -24]. Nevertheless, they have not synthesized in aqueous solution without using stabilizer as polymer ligand salt etc. The purpose of this study was to synthesize, characterize and investigate thermal stability of nickel Nano particles.

\section{Experimental}

\section{Material and Method}

The present study was conducted using reagents and chemicals of analytical grade, phenol, formaldehyde, acetic acid (Central drug house private limited) and hydrochloric acid (Fisher Scientific) were used. The metal solution was prepared by dissolving appropriate amount of metal salt in deionised water. The nickel nanoparticles were prepared by the simple calcination method and characterization was done by IR, NMR, SEM, TEM, XRD and TGA. The method used for the synthesis of metallic nanoparticles is as described by [25]. However, the procedure is summarized in the figure below [26-27].

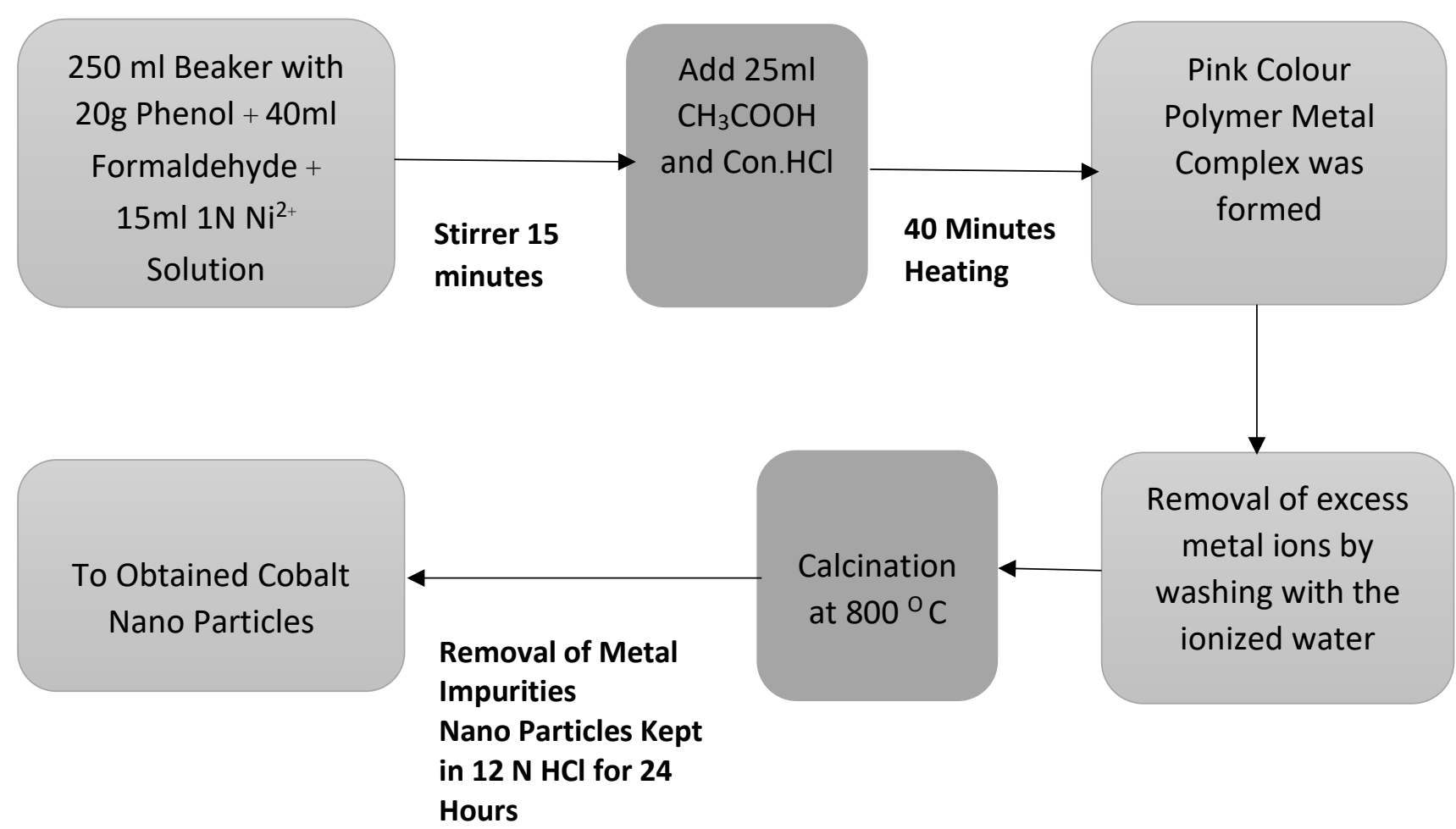


Synthesis of monomer :-<smiles>O=Cc1ccccc1O</smiles><smiles>CC(C)(C)c1ccccc1CO</smiles><smiles>OCc1ccc(O)cc1</smiles>

Polymerization of monomers :-<smiles>CC(C)(C)c1cccc(Cc2cccc(C(C)(C)C)c2O)c1O</smiles>

Novalac (Linear Polymer)

$\mathrm{n}$<smiles>OCc1ccc(O)cc1</smiles>

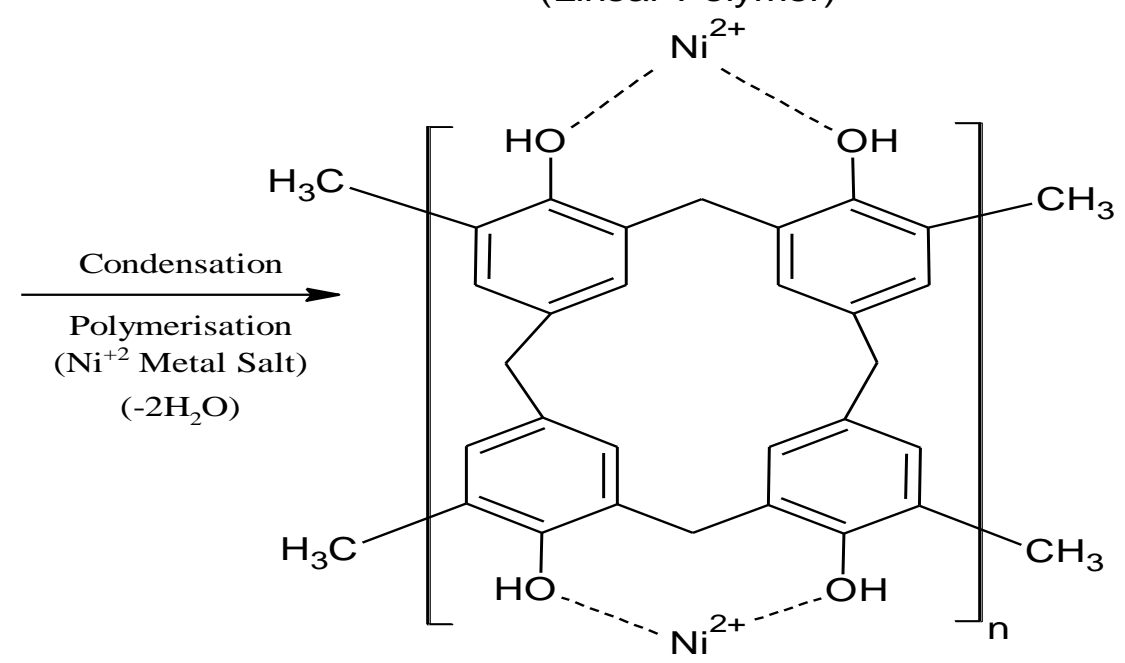

Polvmer Nickel Metal Complex

\section{Reaction Scheme -Synthesis of Nickel doped Phenol-Formaldehyde complex}

\section{Result and discussion -}

FT-IR spectra of nickel doped phenol-formaldehyde complex is shown in figure:1. The assignment of all the characteristic peaks were summarized in table 1 . 
Table 1: FTIR assignment of Nickel doped phenol - formaldehyde complex

\begin{tabular}{|l|l|}
\hline \multicolumn{1}{|c|}{ Prominent absorption band } & \multicolumn{1}{c|}{ Functional Group } \\
\hline $3348 \mathrm{~cm}^{-1}$ & O-H stretching \\
\hline 2891 and $2828 \mathrm{~cm}^{-1}$ & Aliphatic C-H stretching \\
\hline 1701 and $1603 \mathrm{~cm}^{-1}$ & Aromatic C=C stretching \\
\hline $1136 \mathrm{~cm}^{-1}$ & C-OH bending \\
\hline 877 and $^{-162 \mathrm{~cm}^{-1}}$ & $\begin{array}{l}\text { C-H out of plane bending vibrations of } \\
\text { an aromatic ring }\end{array}$ \\
\hline $623 \mathrm{~cm}^{-1}$ & Ni-O stretching \\
\hline
\end{tabular}

The FT-IR spectra of polymer metal complex exhibit a band at $3348 \mathrm{~cm}^{-1}$, which can be assigned to the $\mathrm{O}-\mathrm{H}$ stretching. The $\mathrm{C}-\mathrm{H}$ asymmetrical and symmetrical stretching due to the methylene groups can be observed between 2891 and $2828 \mathrm{~cm}^{-1}$ respectively. The peaks at 1701 and $1603 \mathrm{~cm}^{-1}$ were attributed to the aromatic $\mathrm{C}=\mathrm{C}$ stretching. The bands observed at $1136 \mathrm{~cm}^{-}$ ${ }^{1}$ resulted due to $\mathrm{C}-\mathrm{OH}$ bending. The $\mathrm{C}-\mathrm{H}$ out of plane bending vibrations of the aromatic ring was seen at $880-770 \mathrm{~cm}^{-1}$. The absorption band at $623 \mathrm{~cm}^{-1}$ was observed due to the Ni-O linkage and also confirm the bonding of metal through the oxygen of - $\mathrm{OH}$ functional group of phenolformaldehyde. 


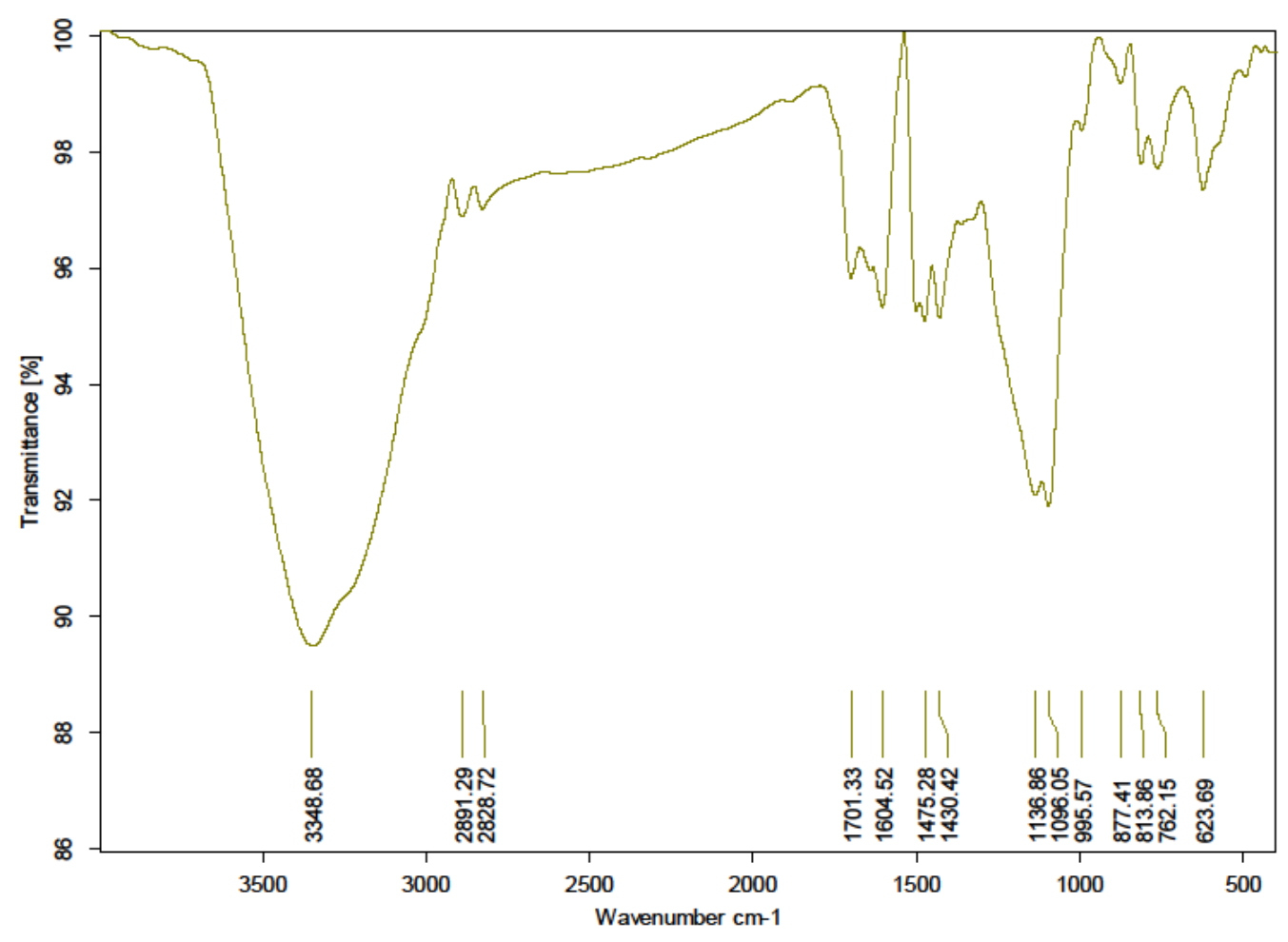

Figure- 1: FTIR Spectra of Nickel doped Phenol - formaldehyde Complex

Figure 2: shows the 1H NMR spectrum of the nickel doped Phenol-Formaldehyde complex. The proton peak at $3.65 \mathrm{ppm}$ exhibit the residual proton signal of DMSO - d6 solvent. The -OH group of phenol gives the proton signal at $5.35 \mathrm{ppm}$. The aromatic proton of phenol gives a multiplet at 7 to $8 \mathrm{ppm}$.

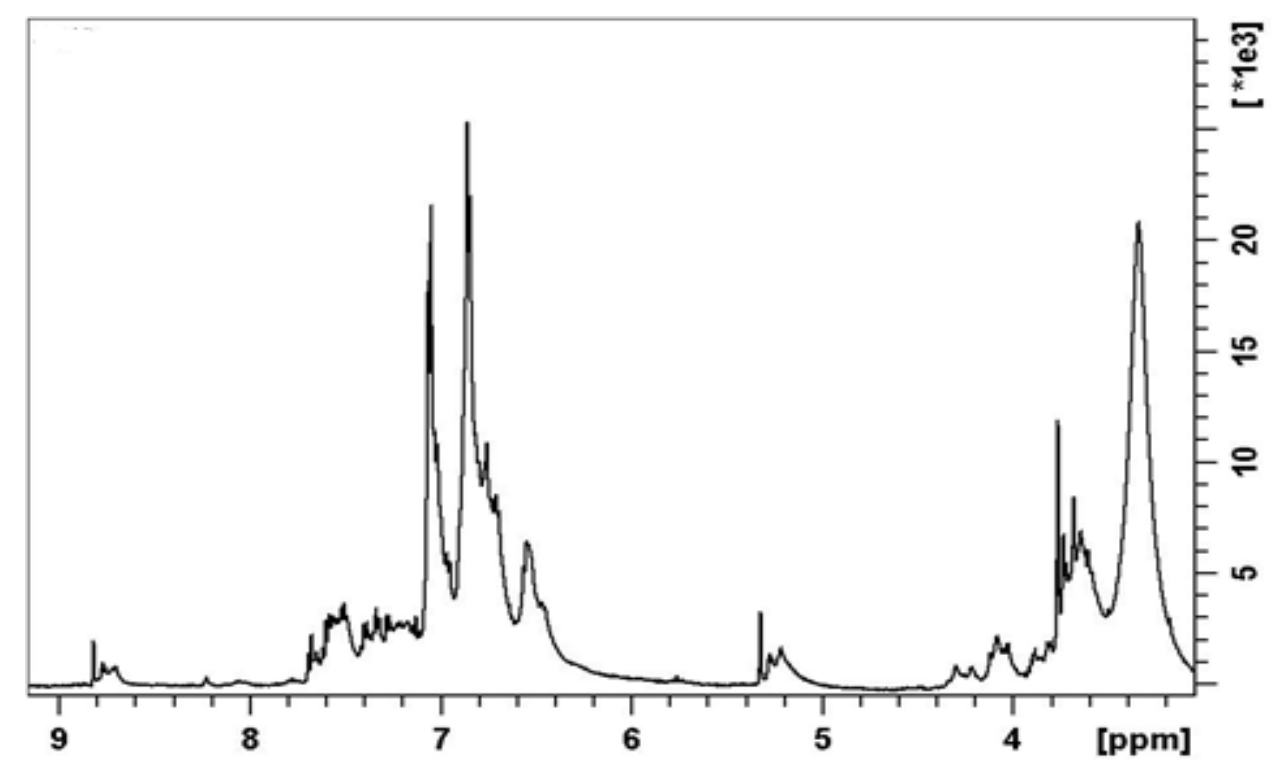

Figure 2: ${ }^{1}$ HNMR Spectra of Nickel doped phenol - Formaldehyde Complex 
The SEM analysis of nickel doped phenol- formaldehyde nanocomposite at 2500, 10000 and 25000 magnifications in figure 3. shows the cluster shape morphology of nickel nanoparticles. The earlier study to support our findings who have also made a similar observation of that the cobalt nanoparticles have a spherical shape. [28,29]. The present study support the finding of Shanaj et al. (2016) who have also made similar observations that the nickel nanoparticles have a spherical shape [30].
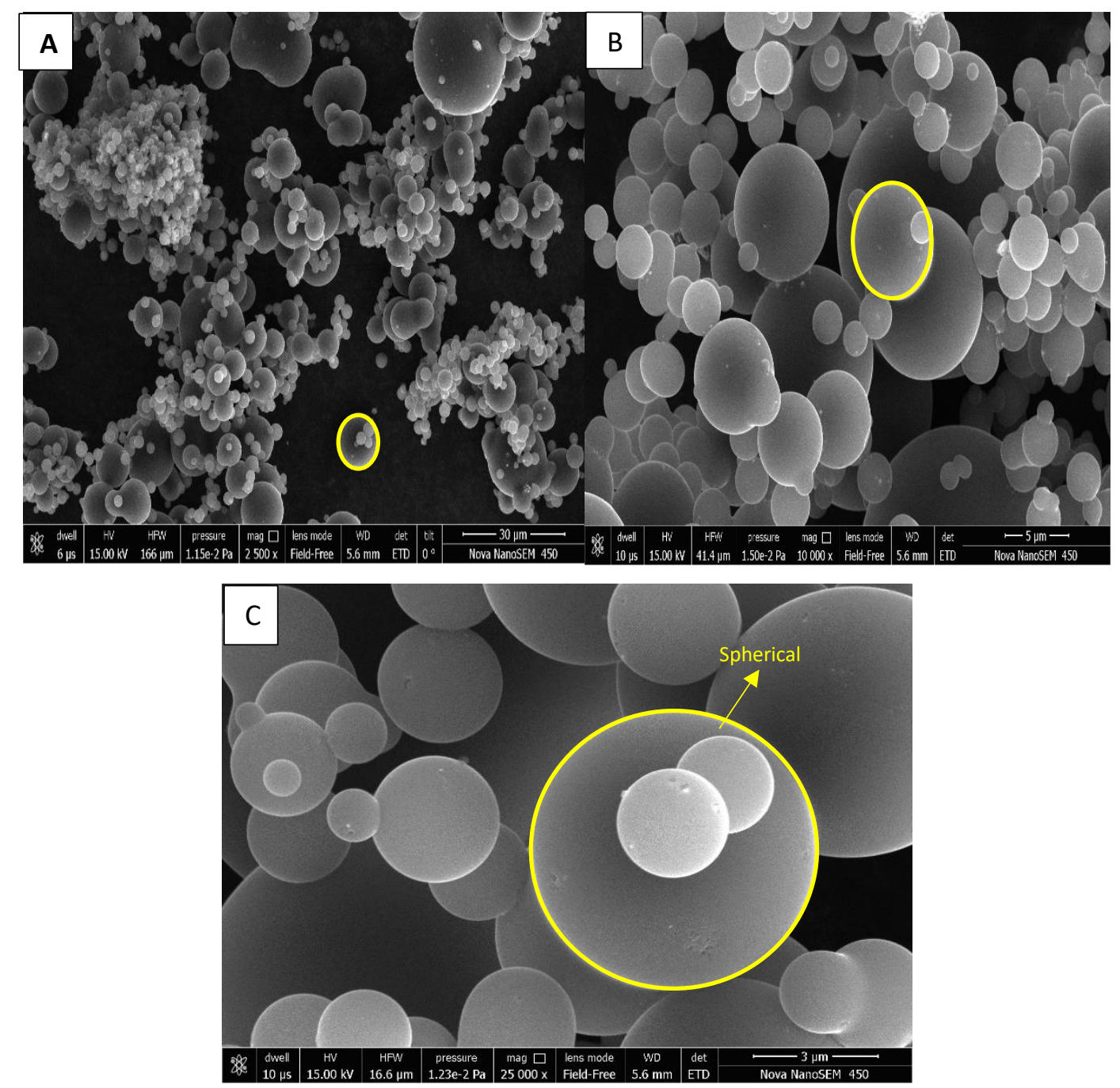

Figure 3: SEM image of Nickel doped Phenol-Formaldehyde nanocomposite at (a) 2500 (b) 10000 (c) 25000 magnification 


\section{XRD analysis-}

XRD pattern showed that the size of nickel nanoparticles was $24.0 \mathrm{~nm}$ and has maximum intensity diffraction peak at $2 \Theta^{1 / 4} 12.50290$ which indicate the presence of crystalline structure and the crystal system is monoclinic [31].

\section{TGA analysis -}

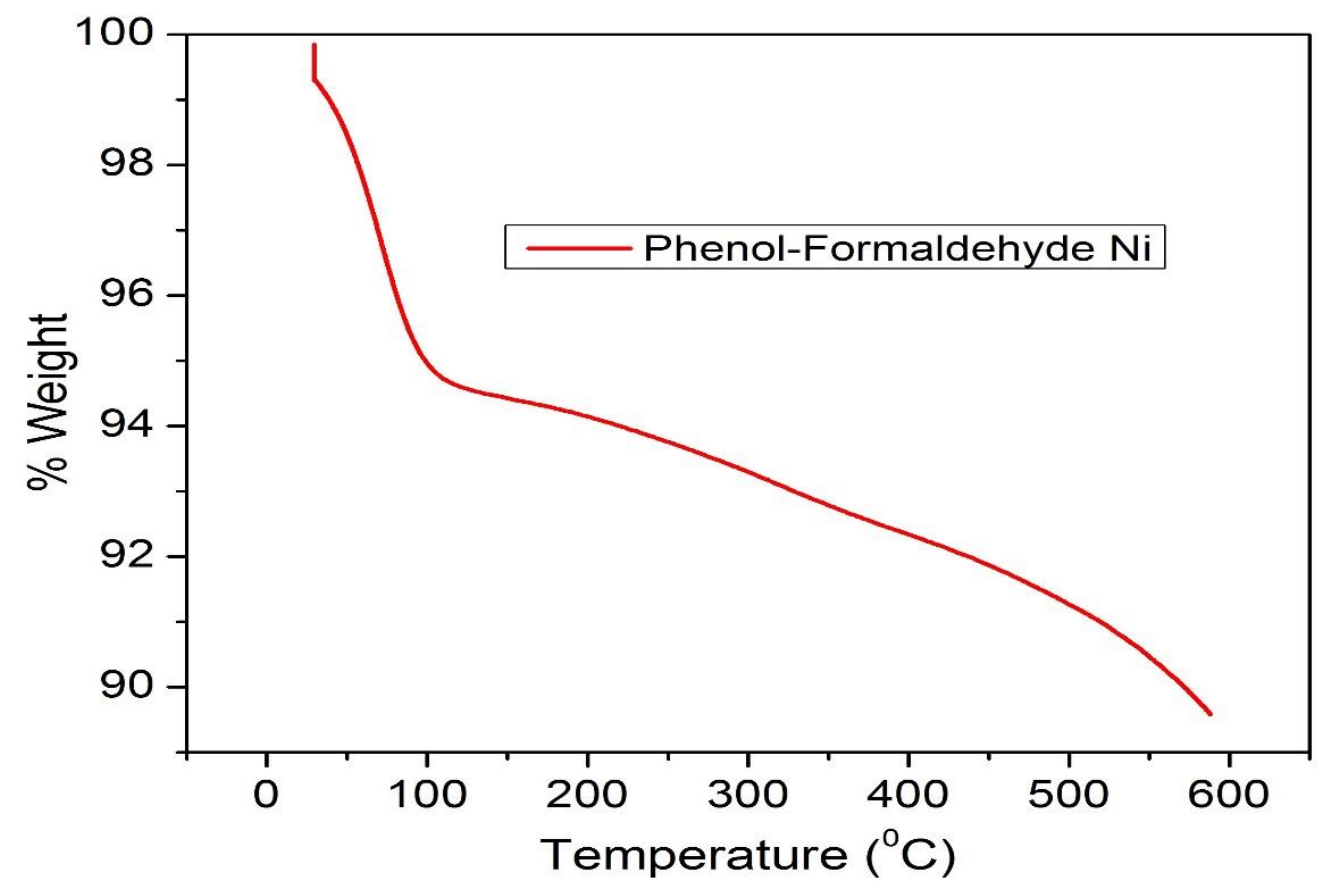

Figure:4 Thermograph of nickel doped phenol-formaldehyde nanocomposite

Table 2: TGA data of Nickel doped phenol-formaldehyde Nanocomposite

\begin{tabular}{|c|c|c|c|c|c|c|}
\hline \multirow{2}{*}{ Sample } & \multicolumn{5}{|c|}{ Weight loss \% } \\
\cline { 2 - 7 } & $100{ }^{\mathrm{O}} \mathrm{C}$ & $200{ }^{\mathrm{O}} \mathrm{C}$ & $300{ }^{\mathrm{O}} \mathrm{C}$ & $400{ }^{\mathrm{O}} \mathrm{C}$ & $500{ }^{\mathrm{O}} \mathrm{C}$ & $600{ }^{\mathrm{O}} \mathrm{C}$ \\
\hline $\begin{array}{c}\text { Nickel doped } \\
\begin{array}{c}\text { Phenol- } \\
\text { formaldehyde } \\
\text { Nanocomposite }\end{array}\end{array}$ & 5.2 & 5.8 & 6.5 & 7.3 & 8.2 & 11.0 \\
\hline
\end{tabular}


Many compounds are not stable and decomposed into some other compound on heating. The TGA thermograph of nickel doped phenol-formaldehyde nanocomposites are shown in figure4. The TGA analysis were performed over a range of $29-600^{\circ} \mathrm{C}$. The TGA thermograph predicts mass decomposition of $11 \%$ for nickel phenol-formaldehyde nanocomposite. The decomposition rate of composites is very low $2 \%$ weight loss per $100^{\circ} \mathrm{C}$ increment in temperature (show in Table:2). The synthesis of thermally stable nickel oxide nanoparticles synthesized by sol-gel method was reported earlier [32] an efficient thermally stable copper nanoparticles formation by chemical precipitation method has been reported earlier by (Chaudhary et.al.2017) [27].

\section{Conclusion -}

The thermally stable nickel nanoparticles were synthesized using a chemical method followed by calcination. The morphological studies by SEM shown the spherical shape of nickel nanoparticles. The size of nickel nanoparticles was predicted by XRD. The thermal stability of nickel nanoparticles major by TGA. The result is well indicative of the efficiency of the chemical precipitation method in the synthesis of nanoparticles. The result as compared with other similar findings revealed that nickel nanoparticles are more thermally stable than copper nanoparticles due to its very less decomposition rate. lastly, these nickel nanoparticles can further be analysed for its thermal properties and application in thermal sensor, thermoelectricity and electronics.

\section{Acknowledgement-}

Authors are grateful to Mrs. Khushbhu Tailor for the preparation of the manuscript. The authors are also thankful to MNIT Jaipur, Rajasthan, M.L.S University, Udaipur, Rajasthan, India for providing the characterization facility. The authors acknowledge to Heads Department of chemistry, M.L.S University and Mewar University for the providing lab facility.

\section{Conflicts of Interest:}

The author(s) declare(s) that there is no conflict of interest regarding the publication of this paper.

\section{Reference-}


[1]. Feygenson M, Kou A, Kreno LE, Tiano AL, Patete JM, Zhang F, Kim MS, Solovyov V, Wong SS, Aronson MC: Properties of highly crystalline NiO and Ni nanoparticles prepared by high-temperature oxidation and reduction. Phys Rev B 2010, 81:014420.

[2]. Baudouin D, Rodemerck U, Krumeich F, de Mallmann A, Szeto KC, Ménard H, Veyre L, Candy JP, Webb PB, Thieuleux C, Copéret C: Particle size effect in the low temperature reforming of methane by carbon dioxide on silica-supported Ni nanoparticles. J Catal 2013, 297:27-34.

[3]. Bussamara R, Eberhardt D, Feil AF, Migowski P, Wender H, de Moraes DP, Machado G, Papaléo RM, Teixeira SR, Dupont J: Sputtering deposition of magnetic Ni nanoparticles directly onto an enzyme surface: a novel method to obtain a magnetic biocatalyst. Chem Commun 2013, 49:1273-1275.

[4]. Lee KB, Park S, Mirkin CA: Multicomponent magnetic nanorods for biomolecular separations. Angew Chem Int Ed 2004, 43:3048-3050.

[5]. Khurana JM, Yadav S: Highly monodispersed PEG-stabilized Ni nanoparticles: proficient catalyst for the synthesis of biologically important spiropyrans. Aust J Chem 2012, 65:314-319.

[6]. Kalita P, Singh J, Singh MK, Solanki PR, Sumana G, Malhotra BD: Ring like self assembled Ni nanoparticles based biosensor for food toxin detection. Appl Phys Lett 2012, 100:093702.

[7]. Ma F, Huang JJ, Li JG, Li Q: Microwave properties of sea-urchin-like Ni nanoparticles. J Nanosci Nanotechnol 2009, 9:3219-3223.

[8]. Roy A, Srinivas V, Ram S, Chandrasekhar-Rao TV: The effect of silver coating on magnetic properties of oxygen-stabilized tetragonal Ni nanoparticles prepared by chemical reduction. $\mathrm{J}$ Phys Condens Matter 2007, 19:346220.

[9]. García-Cerda LA, Bernal-Ramos KM, Montemayor SM, Quevedo-López MA, BetancourtGalindo R, Bueno-Báques D: Preparation of hcp and fcc Ni and Ni/NiO nanoparticles using a citric acid assisted pechini-type method. J Nanomater 2011. doi: 10.1155/2011/162495.

[10]. Ma F, Ma J, Huang JJ, Li JG: The shape dependence of magnetic and microwave properties for Ni nanoparticles. J Magn Magn Mater 2012, 324:205-209.

[11]. Leng YH, Wang YT, Li XG, Liu T, Takahashhi S: Controlled synthesis of triangular and hexagonal Ni nanosheets and their size-dependent properties. Nanotechnology 2006, 17:48344839 .

[12]. Chen WM, Zhou W, He L, Chen CP, Guo L: Surface magnetic states of Ni nanochains modified by using different organic surfactants. J Phys Condens Matter 2010, 22:126003. 
[13]. Wangcharoen W and Morasuk W, J Sci Technol., 2007, 29(5), 1407-1415.

[14]. Chen D and Hsieh C, J Mater Chem., 2002, 12, 2412-2415; DOI:10.1039/B200603K

[15]. Förster H, Wolfrum C and Peukert W 2012 Experimental study of metal nanoparticle synthesis by an arc evaporation/condensation process J Nanopart. Res. 14926.

[16]. Bönnemann H and Richards R M 2001 Nanoscopic Metal Particles - Synthetic Methods and Potential Applications Eur. J. Inorg. Chem. 2001 2455-2480.

[17]. Zhang J and Lan C Q 2008 Nickel and cobalt nanoparticles produced by laser ablation of solids in organic solution Mater. Lett. 62 1521-1524.

[18]. Yu P, Qian Q, Wang X, Cheng H, Ohsaka T and Mao L 2010 Potential-controllable green synthesis and deposition of metal nanoparticles with electrochemical method J. Mater. Chem. $205820-5822$.

[19]. Okitsu Kenji 2011 Sonochemical Synthesis of Metal Nanoparticles: In "Theoretical and Experimental Sonochemistry Involving Inorganic Systems, Ed. Ashokkumar Muthupandian (Netherlands: Springer) p 131-150.

[20]. Chen Y, Peng D-L, Lin D and Luo X 2007 Preparation and magnetic properties of nickel nanoparticles via the thermal decomposition of nickel organometallic precursor in alkylamines Nanotechnology 18505703.

[21]. Xuemin He, Wei Zhong, Chak-Tong Au and Youwei Du, Size dependence of the magnetic properties of Ni nanoparticles prepared by thermal decomposition method, Nanoscale Research Letters 2013, 8:446.

[22]. Xinwei Wang and Xianfan Xu, Thermal Conductivity of Nanoparticle-Fluid Mixture, journal of thermophysics and heat transfer, Vol. 13, No. 4, October-December 1999.

[23]. L. F. Cao, G. Y. Xu, D. Xie, M. X. Guo, L. Luo, Z. Li, and M. P. Wang, Thermal stability of Fe, Co, Ni metal nanoparticles, phys. stat. sol. (b) 243, No. 12, 2745-2755 (2006).

[24]. M. P. Deshpande, Kiran N. Patel, Vivek P. Gujarati, Kamakshi Patel, S. H. Chaki, Structural, Thermal and Optical Properties of Nickel Oxide (NiO) Nanoparticles Synthesized by Chemical Precipitation Method, Advanced Materials Research, ISSN: 1662-8985, Vol. 1141, pp 65-71.

[25]. J. Chaudhary, G. Tailor, D. Kumar, A. Joshi, Synthesis and thermal properties of copper nanoparticles, Asian J. Chem. 29 (7) (2017) 1492-1494.

[26]. J. Chaudhary, G. Tailor, D. kumar, Res. J. Chem. Environ, 2018, 23,3, 10-14. 
[27]. J. Chaudhary, G. Tailor, D. Kumar, A. Joshi, Asian J. Chem. 2017, 29, 7, 1492-1494.

[28]. L. Ajroudi , N. Mliki, L. Bessais, V. Madigou, S. Villain, Ch. Leroux , Magnetic, electric and thermal properties of cobalt ferrite nanoparticles, Materials Research Bulletin , 2014, 59, 49-58.

[29]. J. Chaudhary, G. Tailor, D. Verma, R. Verma Synthesis and Characterization of Cobalt Nanocomposite Using Aniline-Formaldehyde Resin, Composites Communications, 18,2020, 13-18.

[30]. Shanaj BR and John XR, Effect of Calcination Time on Structural, Optical and Antimicrobial Properties of Nickel Oxide NanoparticlesTheor Comput Sci 2016, 3:2.

[31]. J. Chaudhary, G. Tailor, D. Kumar, S.K. Shailesh, Synthesis and structural study of nickel (II) bakelite nanocomposite by X-ray diffaraction, Int. J. Metall. Mater. Sci.

Eng. 6 (2) (2016) 17-20.

[32] Umbreen Ashraf and Bushra Khan. "Synthesis and characterization of Nickel oxide nanopowder by Sol-Gel method". International Journal of Science and Research, 4(5) (2015) 2405-2408. 